\title{
Experiment Research on Insulation Effect of Water Storage Roof Brick In Winter
}

\author{
Rubing $\operatorname{Han}^{1,3, a}$, Zhimao $\mathrm{Xu}^{2, \mathrm{~b}}$ and Yutao Qing ${ }^{1, \mathrm{c}}$ \\ ${ }^{1}$ Southwest University of Science and Technology, Mianyang, China \\ ${ }^{2}$ Sichuan Electric Power Design \& Consulting CO., Itd. Chengdu,China \\ ${ }^{3}$ Sichuan University, Chengdu, China \\ ahanrubing_20050313@163.com, bzmhrb@sohu.com, 'cqyt1991@yeah.net
}

\begin{abstract}
Keywords: water-retaining roof brick; depths of water; ventilation; heat insulation.
Abstract. As an important part of building envelope, roof has a significant impact on attic indoor's energy consumption and thermal environment. Water storage roof bricks have a good heat insulation performance and environmental effect under a certain structure. This paper researches the heat insulation performance of water storage brick with different sunshade hours and water depth to test and analyze heat preservation, and the change rules and characteristics of the temperature among the roof under water storage bricks, the roof under sunshine and outdoor. It is found that sun lighting time of water storage roof bricks has effects on the performance of heat preservation and heat insulation, and the optimum condition is when the water depth is $8 \mathrm{~cm}$. And it provides the basis for optimizing the structure of the water storage roof tiles.
\end{abstract}

\section{Introduction}

Ineffective roofing insulation leads to bad thermal environment of top floor apartment, and heating and air-conditioning load was significantly higher than the standard level. The urban heat island effect and dry island effect are obvious. Indoor heat spreading to the roof in winter is the main factors influencing the room air conditioning (heating) consumption, and the heat has a large influence on indoor thermal comfort of the top-level households. Water storage roof which stores the water of certain thickness on roof is used to improve the insulation performance of roof. The heat accumulated by water is released at night, and it can reduce the heat from the room and improve the thermal comfort of the indoor environment.

The research team develops a water storage roof brick used in existing buildings roofing energy-saving renovation project. As for the geographical area, the water storage roof brick is suitable for the hot summer and cold winter area, where the cumulative freezing time is less than 10 days per year on an average of the last 50 years. The test chooses a not very new building - a university laboratory building which is located in the city of Mianyang. The brick material named ceramsite concrete which is of small proportion and small coefficient of thermal conductivity. But if the ceramsite concrete is used in icing area in winter, it will be at the risk of frost crack. Thus, the ceramsite concrete is suitable for the hot summer and cold winter areas where rare freezing occurs. The testing area is located in Sichuan Mianyang in this experiment. The insulation effect of the ceramsite storage roof brick in winter was measured the working condition of evaporation is simulated .The conclusions of the research provide the basis for roofing energy saving transformation on existing buildings.

\section{Structure of the Ceramsite Concrete Water Storage Brick}

The periphery size of the ceramsite concrete water storage brick model is $300 \mathrm{~mm} \times 300 \mathrm{~mm} \times$ $240 \mathrm{~mm}$. There' re $20 \mathrm{~mm}$ air layer between the bottom of the brick and the roof. The thickness of the bottom of the brick is $20 \mathrm{~mm}$.All other wall thickness and the thickness of the cover is $20 \mathrm{~mm}$. The 
maximum water depth is $120 \mathrm{~mm}$. Fig. 1 shows the structure of the brick. Fig.2 and Fig.3 show the testing data points at the same time.

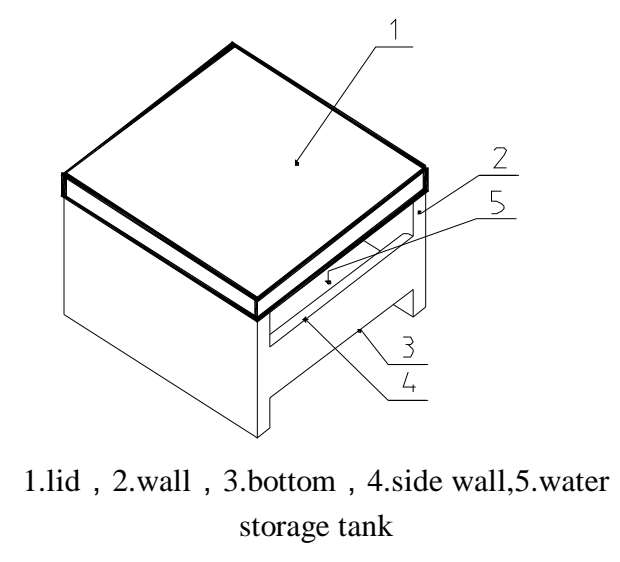

Fig.1.schematics of the test structures

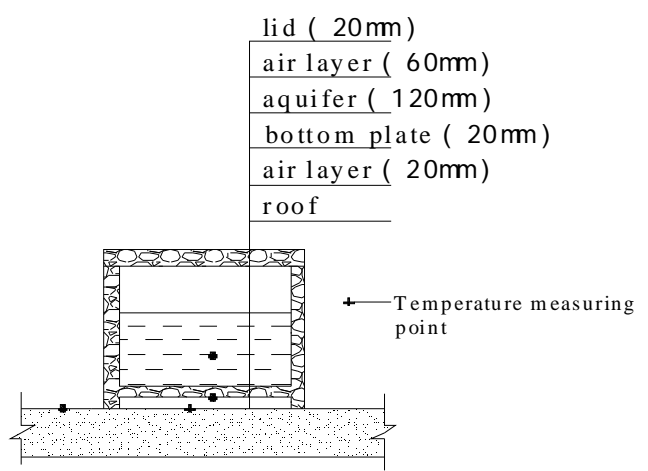

Measuring points: roof, roof with brick, brick bottle, water

Fig.2.Measuring point layout

\section{Measure Points of the Water Storage Brick and Testing Equipment}

Arrangement of the testing points of the water storage brick

The depth of the water in the water storage brick is set by gradient in this experiment, and the maximum depth is only $12 \mathrm{~cm}$. The water depth of the NO.1 and NO.14 water storage brick is $12 \mathrm{~cm}$. The water depth of the NO.2and NO.13 water storage brick is $10 \mathrm{~cm}$. The water depth of the NO.3 and NO.12 water storage brick is $8 \mathrm{~cm}$. The water depth of the NO.4 and NO.6 water storage brick is $6 \mathrm{~cm}$. The water depth of the NO.5 and NO.10 water storage brick is $4 \mathrm{~cm}$. Fig 3 shows the floor plan of the water storage brick.

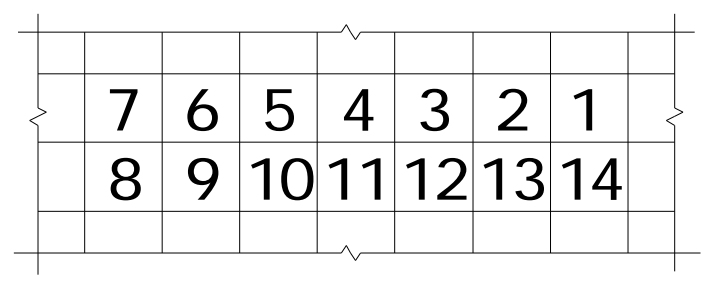

Fig.3.Module floor plan

\section{Test Data Selection}

This experiment was started in January 18, 2015 and ended on February 16, 2015. We select testing data from February 4th , 2015 to February 9th .These days are continuous sunny days including February 5th, February 7th ,February 8th .Thus, we can consider the testing conditions are the same approximately. We contrast and analyze the collected data from the three days.

Data Collection Equipment

Test equipment and operation methods are as follows: the solar total radiation intensity, outdoor wind speed, outdoor air temperature and outdoor air relative humidity.

We use the PC - 4 environment monitoring system made from Mianzhou Sunshine Meteorological Science and Technology Co., Ltd. to monitor the outdoor air relative humidity. The sensitivity of the device is $\pm 0.2^{\circ} \mathrm{C}$. .We record once per minute and select the data of the hour to draw the figure of the changing trend of meteorological parameters. And each temperature of measuring point is tested by Shanghai ZhaoJie paperless recorder C6108A, accuracy class $\pm 0.2 \% \mathrm{FS}$, recorded once every 4 minutes. We choose the hourly data to draw the chart of the temperature changing trend. 


\section{Test Results and Analysis}

\section{Weather Category}

Weather conditions have a greater impact on the insulation effect. In order to evaluate the insulation effect of different water storage brick accurately, we need to classify the weather conditions during the test. Thus, we choose sunny periods (such as sunny days, cloudless days, and strong solar radiation intensity) for thermal control focus sessions by experimental data analysis. Therefore, our present study on the insulation effect of water storage brick is based on sunny periods.

Measuring Meteorological Parameters

Solar Radiation Intensity

Solar radiation intensity is the main factor influencing the water storage roof brick. According to the test during the sunny and cloudy days, the solar radiation intensity distribution characteristics can be seen in table. 1, and we can draw conclusions as below:

(1) The average solar radiation of sunny days is $315.6 \mathrm{w} / \mathrm{m} 2$, cloudy days' average solar radiation intensity is $39.8 \mathrm{w} / \mathrm{m} 2$, and sunny days' average solar radiation intensity is $275.8 \mathrm{w} / \mathrm{m} 2$ higher than cloudy.(2) a maximum of solar radiation is $692.0 \mathrm{w} / \mathrm{m} 2$ in sunny days, which is higher than the largest solar radiation intensity $(69 \mathrm{w} / \mathrm{m} 2)$ in cloudy. In addition, the maximum intensity of solar radiation was always reaches 13:00pm in sunny and cloudy days.(3) Sunny day' s average hourly solar radiation intensity was greater than cloudy days' average hourly solar radiation intensity.

Table.1.radiation statistics

\begin{tabular}{|c|c|c|c|}
\hline Weather & $\underset{\text { Solar radiation }}{\text { ) }}$ & time & difference $(\mathrm{w} / \mathrm{m} 2)$ \\
\hline sunny & $\begin{array}{cc}\text { Max } & 692.0 \\
\text { Min } & 13.0 \\
\text { Average } & 315.6\end{array}$ & $\begin{array}{l}13: 00 \\
8: 00\end{array}$ & 679 \\
\hline cloudy & $\begin{array}{cc}\text { Max } 69.0 \\
\text { Min } 1.0 \\
\text { Average } 39.8 \\
\end{array}$ & $\begin{array}{l}13: 00 \\
8: 00\end{array}$ & 68 \\
\hline
\end{tabular}

Air Temperature and Relative Humidity

During the test for February $4-9$, outdoor air temperature and relative humidity changes are shown in Fig.4. ( Note: AT--air temperature, RH--relative humidity )

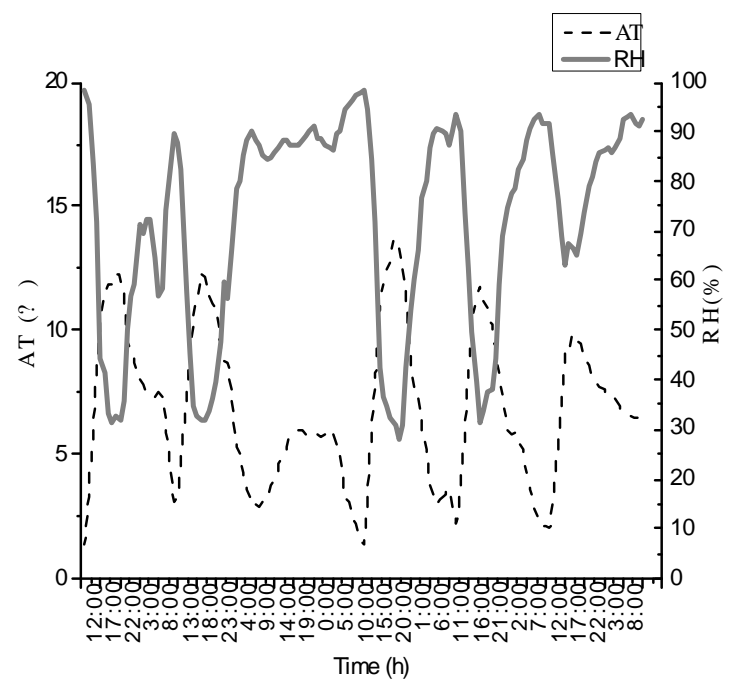

Fig.4.Temperature and humidity of outside (Feb.4-9)

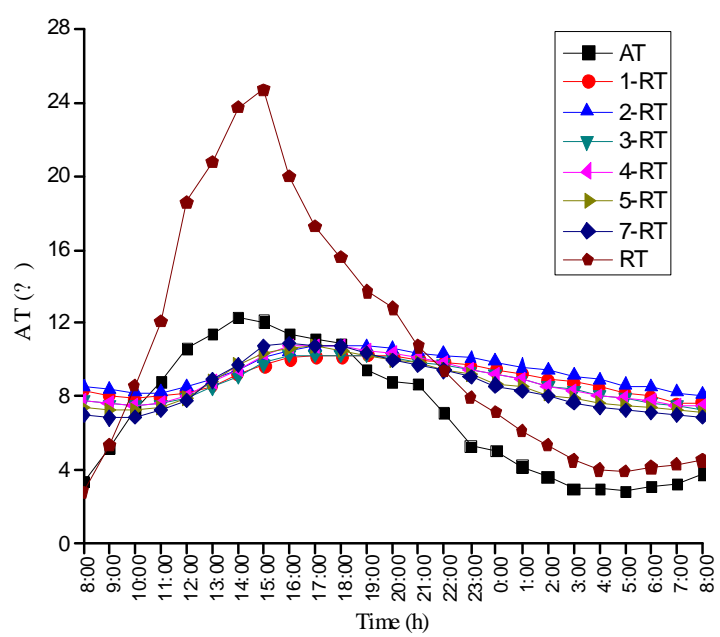

Fig.5.Temperature variations $(\mathrm{A})$ 


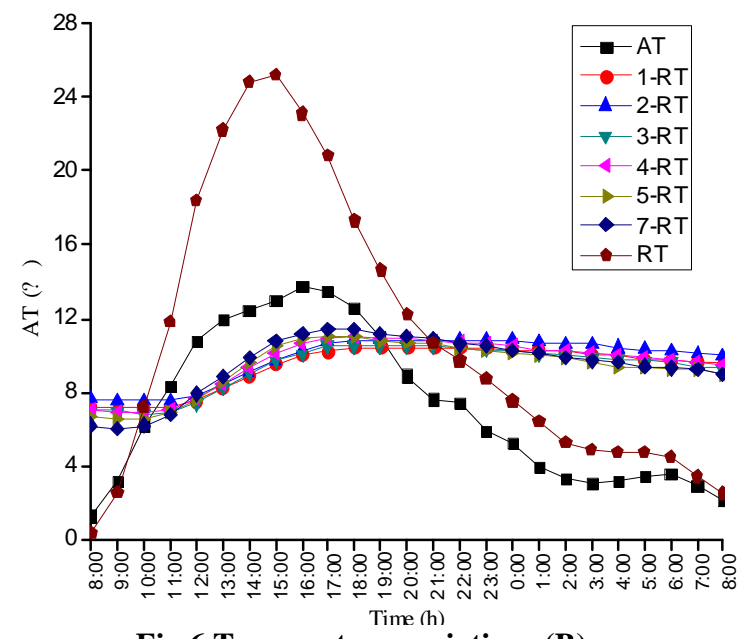

Fig.6.Temperature variations $(\mathrm{B})$

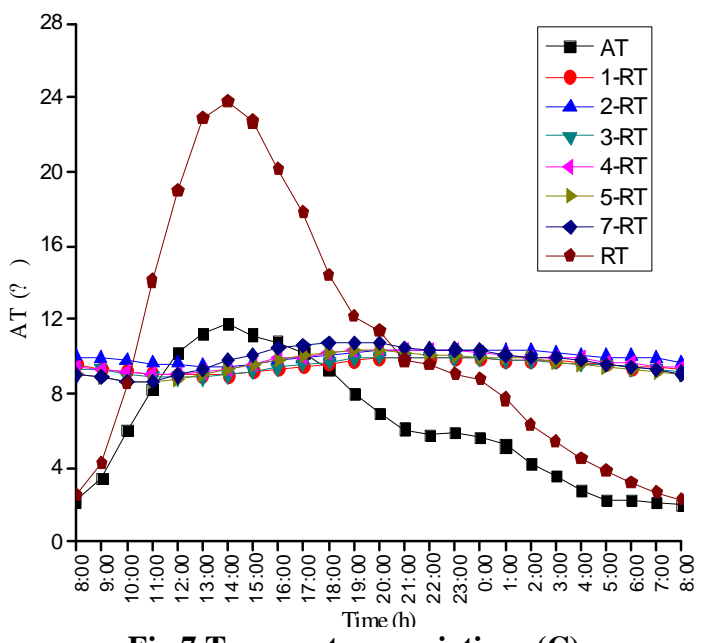

Fig.7.Temperature variations $(\mathrm{C})$

Comparison of temperature between roof with Water Storage Brick and Exposed Roof.

This article compared temperature between roof with water storage brick and exposed roof to study the insulation effect of water storage bricks; we found that roof temperature had deceased after using water storage brick. The temperature comparison is shown in Fig. 5, Fig. 6, and Fig. 7.

\section{A--24 hours without cover , B--8: 00 am. to 18:00 pm. without cover \\ C--24 hours with cover ( AT--air temperature, RT--roof temperature )}

The conclusions can be summarized as follows from Fig.5, Fig.6, and Fig.7:

(1) With the increase of the air temperature, the temperature in the roof under water storage bricks drops, and vice versa. Temperature between air and roof shows a corresponding change in the characteristics, but there is a certain time delay when the maximum temperature occurs. Roof temperature in A (or B) changes more significantly than C.

(2) With the decrease of the air temperature during nights, the temperature in the roof under water storage bricks drops. There is a certain time delay during the temperature change. However, while comparing with the temperature on the exposed roof, the temperature in the roof under water storage bricks changes a little. Meanwhile, roof temperature in B (or C) drops quickly, while compared with A. (3) We draw a conclusion that there is a relationship between water depth and effect of insulation by comparing the insulation effect of water storage brick with different water depth. When the depth of water is $8 \mathrm{~cm}, 10 \mathrm{~cm}$, and $11 \mathrm{~cm}$, the roof temperature with brick changes only $0.6 \square$. The more water storage in the brick, the more roof-load buildings would bear. Thus, we thought the depth of $8 \mathrm{~cm}$ is the best one considering roof bearing and saving water resources. And no need to increase the depth of water deliberately to increase heat insulation performance.

\section{Conclusion}

Through the research on the insulation effect of water storage roof brick, the research group aimed at mastering its warm-kept effect and providing the basis to implement and manage the water storage roofs further. The following conclusions are based on the analysis of the measured data: 
(1) In the test period, water storage brick insulation has the best performance from 8:00 am to 18:00 pm, without cover.

(2) In order to use the water resources rationally and reduce the load of the roof, the best water storage depth in the brick is $8 \mathrm{~cm}$. And no need to continue to increase the depth of water in order to achieve higher thermal insulation effect.

In summary, the ceramic concrete used as brick material has the feature of small coefficient of thermal conductivity, small density, can satisfy the requirement of the existing buildings roofing load-bearing, but there is a danger of frost crack when encounter icing. Therefore, the water storage brick is suitable for the hot summer and cold winter areas where rarely encounter icing weather, and it can be used for both energy-saving building roof, and excellent performance.

\section{Acknowledgements}

This work was supported by National Natural Science Foundation of China (No.51408512).

\section{References}

[1] Yuxin He, in:Building energy consumption ranking first of all types in China. Vol.1 of People's $\operatorname{Daily}(2005)$

[2] Rubing Han, Enshen Long, Zhiyun Wang, One kind of water double insulation brick, China, Patent 2010105871072(2013)

[3] Florides G A, Tassou S A, Kalogirou S A, in:Review of solar and low energy cooling technologies for buildings[J].Renewable and Sustainable Energy Reviews, p. 557-572(2002).

[4] Nahar N M , Sharma P,Purohit M M, in: Performance of different passive techniques for cooling of buildings in arid regions. Building and Environment, p. 109-116(2003).

[5] Sahar N , Kharrufa, Yahyah Adil, in : Roof pond cooling of buildings in hot arid climates. Building and Environment, p. 82-89(2008).

[6] Zahra Ghiabaklou , in : Thermal comfort prediction for a new passive cooling system. Building and Environment, pp. 883-891 ( 2003 ).

[7] Wansheng Yang, Taoli Zhong, in:Experimental study on the evaporation cooling characteristics of a shallow-layer open-type water-retaining roof modular. New Building Materials, p. 40-44(2013).

[8]Wansheng Yang, Yuli Gu, in: Contrastive experimental study on the insulation characteristics of shallow-layer sheltered-type water-retaining roof module. New Building Materials, p. 55-60(2014).

[9] Wansheng Yang,Kaihua Guo.Experimental analysis on the insulation characteristics for vegetation roof in buildings. New Building Materials,p. 40-42(2011). 